\title{
Ban on primate trade seen as threat to animals
}

London. Primatologists are concerned that a new campaign by British anti-vivisectionists to end the captive breeding in source countries and international trade of primates used in research could worsen rather than improve conditions for the animals. The researchers fear that a ban might drive the business underground and shift it to countries less able to make sure that the animals are treated properly.

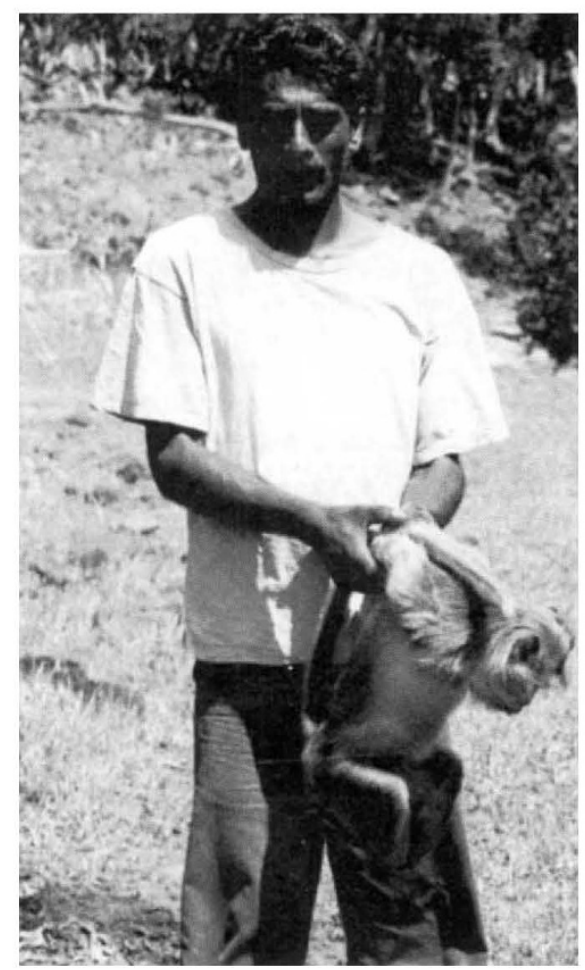

A Mauritian trapper holds a macaque caught in the wild.

Last week, the British Union for the Abolition of Vivisection (BUAV) announced that it would be putting pressure on countries involved in the export of wildcaught primates for research purposes. It singled out Indonesia, the Philippines and the island of Mauritius, all of which were visited by BUAV activists in the course of a year-long investigation. It also claimed that many of the captive breeding programmes it had seen were just a front for extensive trapping in the country concerned.

Groups such as the BUAV have a good record of success on the issue, as Asian countries have generally been responsive to demands that the trade in primates be reduced or stopped. India was one of the largest suppliers of rhesus monkeys in the world until 1978, when it banned their export. Bangladesh introduced a ban in 1979 , and Malaysia in 1984.

But researchers are concerned that such bans, by reducing the sources of supply, may simply transfer the trade to countries less able to meet demand and less experienced in caring for such primate populations. They cite the case of Malaysia, where a ban meant abandoning a small but well-regarded captive breeding programme.

One British primatologist who has spent much time in South-East Asia disputed BUAV's claims that captive-breeding programmes are just a front for wild trapping. In the Philippines, for instance, wild trapping is carried out under strict governmental control, in terms both of how many primates should be taken and from which areas. The Philippine government is committed to reducing the quota for the trapping of feral monkeys by 25 per cent each year while its captive breeding programme is expanded to meet demand.

People who have been involved in setting up supply lines for research primates point to sophisticated captive-breeding programmes in South-East Asia, some of which are of higher quality than those in more developed Western countries. Primatologists and the governments of source countries agree that high-quality captive breeding is the best way to meet the demand for research animals.
Even so, many British researchers and research institutions remain unconvinced that source countries can operate successful captive-breeding programmes. They are unhappy with the current piecemeal nature of regulations, and with the scarcity of documentation accompanying primates from source countries. The Medical Research Council insists that primates should come from within Britain wherever possible, except when a particular species is needed for which no breeding colony exists. The University of Oxford has its own breeding colony, chiefly so that it has control over the condition of the animals.

The BUAV will also be lobbying the British government to impose a ban on the import of wild-caught and captive-bred primates. Current laws allow the use of wildcaught primates in experiments only if there is no other source.

Nevertheless, the relevant legislative committee is concerned about the issue, and it is possible that it may extend the criteria for assessing suffering versus scientific benefit so that the suffering over the whole of the animal's life may be taken into account.

Ian Mundell

\section{Outlook improves for Flemish researchers}

Brussels. The Flemish government is trying to make amends to researchers after four years of harsh treatment. This summer, it is expected to ask its research council to reverse a controversial decision to abolish permanent research posts, after deciding in April to restore BFr60 million (US\$2 million) in research funds. The moves are part of a general government reorganization and reinstitution of policy planning for research - something that has not been possible since 1988, when Belgium was federalized and responsibility for basic research was placed in the hands of its two communities, Flemish-speaking Flanders and Frenchspeaking Wallonia.

The initial government for the Flemish community, which constitutes 58 per cent of the population, did not have a system for protecting basic research. There was no minister with responsibility for science policy, and the prime minister could only juggle the various demands from individual members of parliament. In 1990, the government cut BFr40 million from its BFr1,960 million research budget, and this level of funding was maintained, without any allowance for inflation, for the next two years. The new budget, combined with an already low level of spending, resulted in no new scientific equipment and no additional permanent researchers. Some 5,000 scientists reacted to the worsening conditions by staging a pub- lic protest in February (see Nature 355, 579; 1992).

The new government elected last November is much more sympathetic to the needs of research. The prime minister, Luc van den Brande, now has constitutional responsibility for science policy in Flanders. He has returned BFr60 million to researchers and pledged that future budgets will rise by at least the rate of inflation.

Van den Brande wants to restore the permanent positions immediately as part of an overall restructuring package.

Dirk Callaerts, who advises the prime minister on scientific matters, says that no final decision has been made on the restructuring plan and how permanent research positions may fit into it. "But unless we give researchers a future in Belgium we may lose them altogether", he says.

At present there are 203 permanent posts attached to university laboratories. Never intended to be truly permanent, the positions are used to employ the brightest researchers until they are offered a post within the university system itself. But the system has stagnated; knowing that the research posts will be lost if the current incumbent leaves, universities are loath to hire anyone. By contrast, in French-speaking Belgium, eight or nine permanent posts have been added each year since federalization.

Alison Abbott 